\title{
OPEN Cerebral hemodynamics during neonatal transition according to mode of delivery
}

\author{
Aya Morimoto ${ }^{1}$, Shinji Nakamura ${ }^{1 凶}$, Masashiro Sugino ${ }^{2}$, Kosuke Koyano ${ }^{3}$, Noriko Fuke ${ }^{1}$, \\ Makoto Arioka ${ }^{1}$, Yasuhiro Nakao ${ }^{1}$, Ami Mizuo ${ }^{1}$, Mari Matsubara ${ }^{1}$, Yuta Noguchi ${ }^{1}$, \\ Katsufumi Nishioka ${ }^{1}$, Takayuki Yokota ${ }^{1}$, Ikuko Kato ${ }^{1}$, Yukihiko Konishi ${ }^{1}$, Sonoko Kondo ${ }^{1}$, \\ Jun Kunikata ${ }^{5}$, Takashi Iwase ${ }^{1}$, Saneyuki Yasuda ${ }^{4}$ \& Takashi Kusaka ${ }^{1}$
}

Cerebral haemodynamics during the immediate transition period in neonates may differ depending on whether delivery is vaginal or by caesarean section. However, these differences have never been confirmed by near-infrared time-resolved spectroscopy (TRS). Therefore, the purpose of this study was to compare cerebral blood volume (CBV) and cerebral haemoglobin oxygen saturation $\left(\mathrm{ScO}_{2}\right)$ between healthy term neonates by mode of delivery. Subjects were 31 healthy term neonates who did not require resuscitation. Thirteen neonates were delivered vaginally (VD group) and 18 were delivered by elective caesarean section (CS group). Absolute oxyhaemoglobin, deoxyhaemoglobin, and total haemoglobin concentrations were measured continuously by TRS; oxy Hb $\times 100 /$ total $\left.\mathrm{Hb}_{(\mathrm{ScO}}\right)(\%)$ and CBV ( $\mathrm{mL} / 100 \mathrm{~g}$ brain tissue) were also calculated. Measurements were started as soon as possible after birth, obtained from 1 to 2 min after birth, and continued until 15 min after birth. CBV was significantly higher in the VD group than in the CS group in the $4 \mathrm{~min}$ after birth but not thereafter. There were no significant between-group differences in $\mathrm{ScO}_{2}$ and $\mathrm{SpO}_{2}$. These findings indicate that there is a difference in cerebral haemodynamic patterns in the first 4 min after delivery between term neonates by mode of delivery when CBV is monitored by TRS.

Newborn infants are subjected to a dramatic environmental change at the time of birth and must adapt rapidly to life in the extrauterine environment. The transition from foetal to newborn life is a major physiological challenge that all humans must overcome to survive. In almost all cases, the transition to pulmonary breathing at birth occurs without impediment.

However, adaptation of cardiac function after birth is affected by many factors during the perinatal period. Differences in foetal perfusion related to the mode of delivery (vaginal or caesarean section) may influence foetal haemodynamics. Umbilical arterial adenosine and catecholamine concentrations have been found to differ significantly between neonates born vaginally and those born by caesarean section ${ }^{1}$, suggesting that early neonatal cardiovascular patterns may differ according to mode of delivery.

The neonatal resuscitation guideline now recommends routine monitoring with pulse oximetry/electrocardiography ${ }^{2}$. These two non-invasive continuous monitoring methods enable measurement of the arterial oxygen saturation $\left(\mathrm{SpO}_{2}\right)$ and heart rate. However, few studies have investigated whether there are any differences in neonatal haemodynamic patterns according to mode of delivery when using these parameters ${ }^{3-5}$.

There is increasing interest in additional monitoring of neonates during the immediate transition period using near-infrared spectroscopy (NIRS). NIRS is non-invasive and can detect changes in oxyhaemoglobin (oxyHb) and deoxyhaemoglobin (deoxyHb) concentrations in cerebral tissue. There have been several reports on use of NIRS to measure cerebral oxygenation via the tissue oxygenation index or regional saturation of oxygen in neonates during the immediate transition after birth ${ }^{6-12}$. We have previously reported a difference in the pattern of cerebral haemoglobin $(\mathrm{Hb})$ oxygen saturation $\left(\mathrm{ScO}_{2}\right)$ during the first 15 min after birth according to whether delivery is vaginal or by caesarean section ${ }^{13,14}$. In contrast, Urlesberger et al. found no differences in regional oxygen saturation in the brain according to mode of delivery ${ }^{6}$.

\footnotetext{
${ }^{1}$ Department of Pediatrics, Faculty of Medicine, Kagawa University, 1750-1 Miki-cho, Kita-gun, Kagawa 761-0793, Japan. ${ }^{2}$ Division of Neonatology, Shikoku Medical Center for Children and Adults, Zentsuji, Japan. ${ }^{3}$ Maternal Perinatal Center, Faculty of Medicine, Kagawa University, Kita-gun, Japan. ${ }^{4}$ Post Graduate Clinical Education Center, Kagawa University Hospital, Kita-gun, Japan. ${ }^{5}$ Clinical Research Support Center, Kagawa University Hospital, Kita-gun, Japan. ${ }^{\varpi}$ email: shinji98@med.kagawa-u.ac.jp
} 


\begin{tabular}{|l|l|l|l|}
\hline & Vaginal delivery $(\mathbf{n}=13)$ & Caesarean section $(\mathbf{n}=18)$ & $P$ value \\
\hline Gestational age (weeks) & $39.7(1.0)$ & $38.5(1.0)$ & 0.002 \\
\hline Birth weight $(\mathrm{g})$ & $3281(383)$ & $2806(378)$ & 0.002 \\
\hline Apgar score at 1 min & $8(0)$ & $8(0.4)$ & 0.64 \\
\hline Apgar score at 5 min & $9(0.3)$ & $9(0.3)$ & 0.76 \\
\hline pH in umbilical artery & $7.314(0.04)$ & $7.285(0.05)$ & 0.12 \\
\hline Venous haemoglobin at 2 h $(\mathrm{g} / \mathrm{dL})$ & $18.5(2.4)$ & $18.1(2.0)$ & 0.59 \\
\hline
\end{tabular}

Table 1. Demographic and clinical data of term neonates according to mode of delivery. Data are show as the mean (standard deviation). Neonates delivered by elective caesarean section were significantly lighter than those delivered vaginally because elective caesarean section is performed from a gestational age of 38 weeks in our hospital.

NIRS can also measure the changes in cerebral $\mathrm{Hb}$ concentration $(\mathrm{tHb})$ and cerebral blood volume (CBV), with some work showing a decrease in CBV in term neonates in the first 15 min after birth ${ }^{7}$. Near-infrared time-resolved spectroscopy (TRS) is a unique method for calculating not only quantitative $\mathrm{ScO}_{2}$ but also CBV; it uses a light-absorption coefficient without inducing changes in light-absorbing materials, such as oxygenated $\mathrm{Hb}$ and indocyanine green, because the respective light-reduced scattering and absorption coefficients can be determined by resolving the photon diffusion equation ${ }^{15}$. We have already demonstrated that TRS can stably measure cerebral haemodynamics despite the dramatic physiological changes that occur during labour in the transition period ${ }^{16}$. However, there are still no reports on the differences in absolute CBV patterns in healthy term neonates according to mode of delivery.

In this study, we hypothesised that changes in CBV would be less in infants delivered by elective CS than in those who delivered vaginally and, investigated the changes in absolute CBV during the immediate transition period in healthy infants according to whether delivery was vaginal or by elective caesarean section and how the CBV pattern differed between the two modes of delivery.

\section{Results}

Thirty-seven healthy term infants were delivered vaginally $(n=17)$ or by elective caesarean section $(n=20)$ at Kagawa University Hospital during the study period. Two neonates delivered by caesarean section were excluded because of the need for respiratory support after delivery and four neonates delivered vaginally were excluded because of an abnormal $\mu s^{\prime}$ value, leaving 31 infants for analysis (VD group, $n=13$; CS group, $n=18$ ) (Table 1). The gestational age at delivery was 37-41 weeks and the Apgar scores at 1 min were $\geq 7$.

CBV peaked at about 1-3 min after birth, gradually decreased until $15 \mathrm{~min}$, and then stabilised in both groups. $\mathrm{CBV}$ was significantly higher in the 4 min after birth in the VD group than in the CS group (difference $=\mathrm{VD}-\mathrm{CS}$; mean [95\%CI]: 0.3 [0.0-0.7], $\mathrm{P}=0.039$; linear mixed model) [(Fig. 1A) VD/CS group mean [95\% CI] mL/100 g brain tissue: $1.5 \mathrm{~min}, 2.8[2.5-3.0] / 2.3[2.1-2.5] ; 2 \mathrm{~min}, 2.8[2.6-3.0] / 2.3[2.1-2.5] ; 3 \mathrm{~min}, 2.8[2.6-3.0] / 2.4$ [2.1-2.6]; $4 \mathrm{~min}, 2.7$ [2.4-2.9]/2.3 [2.1-2.5]; $5 \mathrm{~min}, 2.6$ [2.3-2.8]/2.3 [2.1-2.5]; $10 \mathrm{~min}, 2.3$ [2.0-2.5]/2.1 [1.9-2.3]; and $15 \mathrm{~min}, 2.2[1.9-2.4] / 2.0[1.8-2.2]]$.

$\mathrm{ScO}_{2}$ shows the same pattern as $\mathrm{SpO}_{2}$, namely, a gradual increase, a peak at 5-10 min, and then stabilizing thereafter [(Fig. 1B) VD/CS mean [95\%CI]\%: $1.5 \mathrm{~min}, 53.3$ [48.6-58.0]/48.8 [45.0-52.6]; $2 \mathrm{~min}, 56.2$ [51.8-60.7]/51.9 [48.1-55.7]; $3 \mathrm{~min}, 61.8$ [57.4-66.3]/57.2 [53.5-61.0]; $4 \mathrm{~min}, 67.2$ [62.7-71.6]/64.0 [60.2-67.8]; $5 \mathrm{~min}, 68.7$ [64.2-73.1]/67.7 [64.0-71.5]; $10 \mathrm{~min}, 70.4$ [66.0-74.9]/71.0 [67.2-74.7]; and $15 \mathrm{~min}, 69.1$ [64.0-74.2]/70.4 [66.5-74.3]] There was no significant difference in $\mathrm{ScO}_{2}$ between the two groups (p-values by linear mixed model: $1.5 \mathrm{~min}, 0.14 ; 2 \mathrm{~min}, 0.14 ; 3 \mathrm{~min}, 0.12 ; 5 \mathrm{~min}, 0.75 ; 10 \mathrm{~min}, 0.85$; and $15 \mathrm{~min}, 0.70)$. There was also no significant difference between the groups in $\mathrm{SpO}_{2}$ (Fig. 1C).

HR peaked at about 1-3 min after birth, gradually decreased until about $15 \mathrm{~min}$ in the VD group and $8 \mathrm{~min}$ in the CS group, and then stabilised in both groups. HR was significantly higher until 5 min after birth in the VD group compared with the CS group (difference = VD - CS; mean [95\%CI]: 15.1 [2.8-27.5], P=0.017; linear mixed model), and then tended to be higher in the VD group until about 12 min after birth [(Fig. 1D) $\mathrm{VD} / \mathrm{CS}$ group mean $[95 \% \mathrm{CI}] \mathrm{mL} / 100 \mathrm{~g}$ brain tissue: $1.5 \mathrm{~min}, 183.0$ [171.4-194.6]/161.1 [149.0-173.2]; $2 \mathrm{~min}, 180.0$ [170.5-189.5]/167.4 [158.4-176.4]; $3 \mathrm{~min}, 183.3$ [173.8-192.8] / 162.9 [154.7-171.2]; $4 \mathrm{~min}$, 180.2 [170.9-189.5]/163.4 [155.1-171.6]; $5 \mathrm{~min}, 176.7$ [167.4-186.0]/161.6 [153.5-169.7]; $10 \mathrm{~min}, 165.9$ [156.8-175.0]/155.4 [147.3-163.5]; $12 \mathrm{~min}, 166.8$ [157.7-175.9] / 153.5 [145.3-161.6]; and $15 \mathrm{~min}, 153.2$ [143.7-162.7]/156.8 [148.2-165.4]].

Next, we examined the concentrations of oxyHb and deoxyHb at 30-s intervals from 2 to 5 min after birth by two-way analysis of variance (with repeated measures) between the VD and CS groups. The oxyHb concentration tended to be higher in the VD group than in the CS group at 2.5-3.5 min after birth. However, there was no difference in deoxyHb concentration between the groups.

\section{Discussion}

The two main findings of this study were as follows: (1) CBV was significantly higher in the VD group than in the CS group in the first $4 \mathrm{~min}$ after delivery but decreased thereafter during the first $15 \mathrm{~min}$ in both groups and (2) there was an increase in $\mathrm{ScO}_{2}$ including $\mathrm{SpO}_{2}$, but it was not significantly different between these delivery modes. This is the first study to show that CBV is a cerebral haemodynamic parameter that is significantly affected 

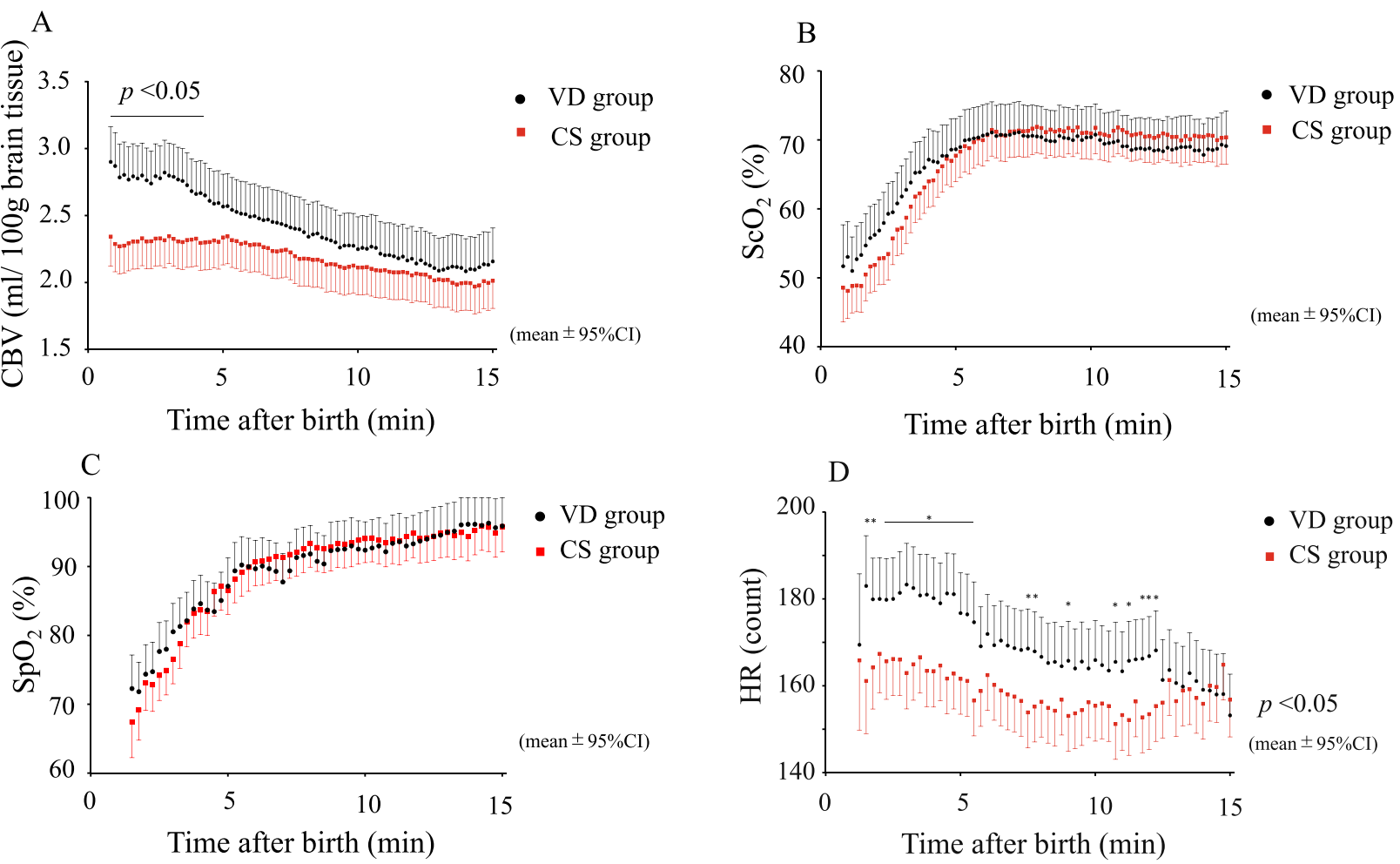

Figure 1. Time course of $\mathrm{CBV}(\mathbf{A}), \mathrm{ScO}_{2}(\mathbf{B}), \mathrm{SpO}_{2}$ (C), and $\mathrm{HR}$ (D) during the first 15 min after birth in healthy neonates in the VD group (black) and the elective CS group (red). The values are shown as the mean (95\% confidence interval [CI] of the mean); $P<0.05$, group comparisons by linear mixed model. $C B V$ cerebral blood volume, $\mathrm{CS}$ caesarean section, $\mathrm{ScO}_{2}$ cerebral haemoglobin oxygen saturation, $\mathrm{SpO}_{2}$ arterial oxygen saturation, $V D$ vaginal delivery.

by mode of delivery in the neonate. Furthermore, this was the first time TRS using probes with a bent tip was applied to neonates and the procedure was determined to be feasible during the transition period after birth.

Schwaberger et al. reported a decrease in CBV within 15 min of birth in healthy neonates delivered by caesarean section, and Noori et al. demonstrated a decrease in cerebral blood flow (CBF) in preterm infants after birth using Doppler sonography ${ }^{17}$. Our study showed a decrease in CBV within 15 min after birth not only in CS, but also in VD, consistent with those previous studies. These decreases in CBF and CBV during postnatal transition may have significant clinical implications, although the relation between CBF and CBV in neonates remains unclear. Schwaberger et al. speculated that the cause of this reduction in CBF was an increase in arterial oxygen content and/or changes in shunting through the ductus arteriosus during the transition period ${ }^{7}$. We speculate that another factor that may contribute to the decrease in CBV within the first 15 min after birth is clamping of the umbilical cord postpartum. In a study in newborn lambs by Polglase et al., CBF increased rapidly within the first $60 \mathrm{~s}$ after cord clamping and remained elevated throughout the entire ventilation period. The authors attributed the rapid increase in $\mathrm{CBF}$ to a combination of haemodynamic responses to clamping of the umbilical cord (i.e., removal of the capacitance placental circulation) ${ }^{18}$.

In this study, CBV was significantly higher in the VD group than in the CS group during the first 4 min after birth but was similar in the two groups by 10-15 min after birth. A possible explanation for the higher CBV within the first 4 min after birth could be the hypoxia that occurs during labour and passage through the birth canal, which causes the marked antepartum difference between normal vaginal delivery and elective caesarean section. There are a few reports on cerebral haemodynamics during labour ${ }^{19-21}$. Uterine contractions result in a decline in foetal $\mathrm{PaO}_{2}$ by approximately $25 \%$, but the majority of appropriately grown, healthy, term foetuses are able to withstand this effect. This hypoxia stimulated the brain stem to increase both the parasympathetic and sympathetic outflow, which induces profound peripheral vasoconstriction. This leads to hypertension and increases the descending aortic pressure, which in turn increases the right ventricular afterload, encouraging passage of blood from the right atrium through the foramen ovale into the left atrium and then the left ventricle, thereby increasing blood flow into the ascending aorta as well as cerebral blood flow ${ }^{22}$. In one previous report, CBV was increased by labour and pushing during the second stage of labour, and the change in CBV after birth in our study is consistent with that report ${ }^{19}$. Such hypoxia to the degree caused by labour is not a serious problem in the process of birth, because the foetus responds to physiological compensations; therefore, blood gas data after birth was in the normal range. This is similar to previous reports that UApH does not differ by mode of delivery ${ }^{1,6}$. However, elective CS without labour might not show these compensatory reactions as is the case with labour before birth in vaginal delivery. CBF might not increase and thus there will be less of an increase in CBV. 
TRS can determine the absolute total $\mathrm{Hb}$ value, which consists of oxyHb and deoxyHb. In this study, the finding of a higher oxyHb in our VD group indicates that vasodilation in the cerebral arterial circulation might be more marked in neonates delivered vaginally than in those delivered by elective caesarean section. Furthermore, sympathetic activation by certain stressors, such as mechanical compression of the head, can promote incretion of catecholamines, and the foetus becomes ready for birth while maintaining its cerebral haemodynamics. There are some reports on the foetal response to hypoxia that focus on cerebral haemodynamics and oxygenation $^{23-25}$. One study showed that when acute hypoxia is detected by chemoreceptors in the carotid body, there is an increase in sympathetic and parasympathetic outflow from the brain stem, which triggers an increase in CBF and cerebral perfusion ${ }^{22}$.

Although there was no significant difference in $\mathrm{ScO}_{2}$, between the two delivery modes, it tended to be higher in the VD group than in the CS group at $5 \mathrm{~min}$ after birth. Pichler et al. found significantly higher $\mathrm{ScO}_{2}$ in a VD group than in a CS group at 4 and $5 \mathrm{~min}$ after birth. They speculated that this difference in $\mathrm{ScO}_{2}$ may reflect differences in $\mathrm{CBF}$, likely as a result of cerebral autoregulation, which may be caused by the difference in arterial oxygen content between $\mathrm{VD}$ and $\mathrm{CS}^{8}$. The reason why there was no significant difference in $\mathrm{ScO}_{2}$ in our study within $5 \mathrm{~min}$ after birth was that oxyHb tended to be higher in VD than in CS, but deoxyHb had the same decreasing pattern in both groups.

HR was higher in the VD group than in the CS group in this study, which is consistent with previous reports $^{8,26}$. In contrast, Almaazmi et al. reported that HR was almost identical in healthy term infant regardless of mode of delivery ${ }^{9}$. We speculate that the lack of significant differences between the two groups may be attributable to arrested labour in their study. CBV depends on cardiac output and vascular resistance. When HR is used as a measure of cardiac output, the difference in HR suggests that CBV differs by mode of delivery. However, in this study, we measured only cerebral haemodynamics and oxygenation; we did not measure systemic haemodynamics except for HR. We checked the venous blood gas in all neonates $2 \mathrm{~h}$ after birth and calculated CBV but could not obtain neonatal blood gas measurements immediately after birth as an indicator of the stress caused by delivery. Furthermore, the number of neonates was too small to define a range of CBV. The early CBV data obtained at around $2 \mathrm{~min}$ did not provide enough information about the initial process of cerebral haemodynamic adaptation to the extrauterine environment. In our next study, we will measure these data earlier such as before cord clamping throughout delivery. Healthy neonates born by vaginal delivery had a significantly higher CBV than those born by elective caesarean section in the immediate transition period, although there was no significant difference in $\mathrm{ScO}_{2}$. This difference in $\mathrm{CBV}$ between the two delivery modes may reflect a difference in cerebral arterial vasodilation, which may be more pronounced in response to hypoxia during passage through the birth canal in neonates born by vaginal delivery. CBV has the potential to be a useful parameter for understanding the initial process of cerebral haemodynamic adaptation after birth.

\section{Methods}

This prospective observational study was performed at Kagawa University Hospital and involved term neonates (gestational age $>37$ weeks, birth weight $>2300 \mathrm{~g}$ ) born by vaginal delivery or elective caesarean section, which was performed under spinal anaesthesia, between October 2012 and April 2019.

After cord clamping, which is performed routinely after $30 \mathrm{~s}$, the neonates were placed in a supine position and breathed room air on the resuscitation table under an overhead heater. A neonatologist observed the transition of each newborn infant and recorded Apgar scores at 1 and $5 \mathrm{~min}$. Resuscitation was performed in accordance with the Neonatal Cardiac Pulmonary Resuscitation 2015 guidelines. A portable three-wavelength TRS system (TRS-21; Hamamatsu Photonics K.K., Hamamatsu, Japan) was used. As soon as possible after delivery, another neonatologist attached the TRS optical probe to the newborn's forehead on the right side and obtained measurements continuously for $15 \mathrm{~min}$ (Fig. 2A). At the same time, a transcutaneous pulse oximeter (Nellcor; Covidien, Mansfield, MA) was applied to the right hand for simultaneous measurement of $\mathrm{SpO}_{2}$.

The following exclusion criteria were applied: (1) a need for any form of respiratory support, such as oxygen, continuous positive airway pressure, or artificial ventilation; (2) hospitalisation due to hypoglycaemia or infection; (3) emergency caesarean section because of obstructed labour and foetal distress; and (4) abnormal optical properties in reference to our previous published data $a^{27}$, namely, a light-reduced scattering value $>9.0 / \mathrm{cm}(2 \mathrm{SD})$.

Near-infrared time-resolved spectroscopy. TRS uses a time-correlated single-photon counting technique for detection. The system was controlled by a computer through a digital I/O interface that consisted of a three-wavelength $(762,800$, and $836 \mathrm{~nm})$ picosecond light pulser as the pulse light source, a photon-counting head for single-photon detection, and signal-processing circuits for time-resolved measurement. The re-emission profiles observed at each measurement point were fitted with the photon diffusion equation proposed by Patterson et al. ${ }^{28}$ to calculate the absorption coefficient $(\mu \mathrm{a})$ and the reduced scattering coefficient $\left(\mu \mathrm{s}^{\prime}\right)$ values of the head at wavelengths of 762,800 , and $836 \mathrm{~nm}$.

In each iterative calculation, the photon diffusion equation was calculated in reflectance mode and was convoluted with the instrumental response; it was then fitted to the observed re-emission profile. After determination of the $\mu \mathrm{a}$ and $\mu \mathrm{s}^{\prime}$ values at the three wavelengths, the oxyHb and deoxyHb concentrations were calculated from their respective absorption coefficients using the following equations, based on the assumption that the background absorption was due to $85 \%$ (by volume) water. 

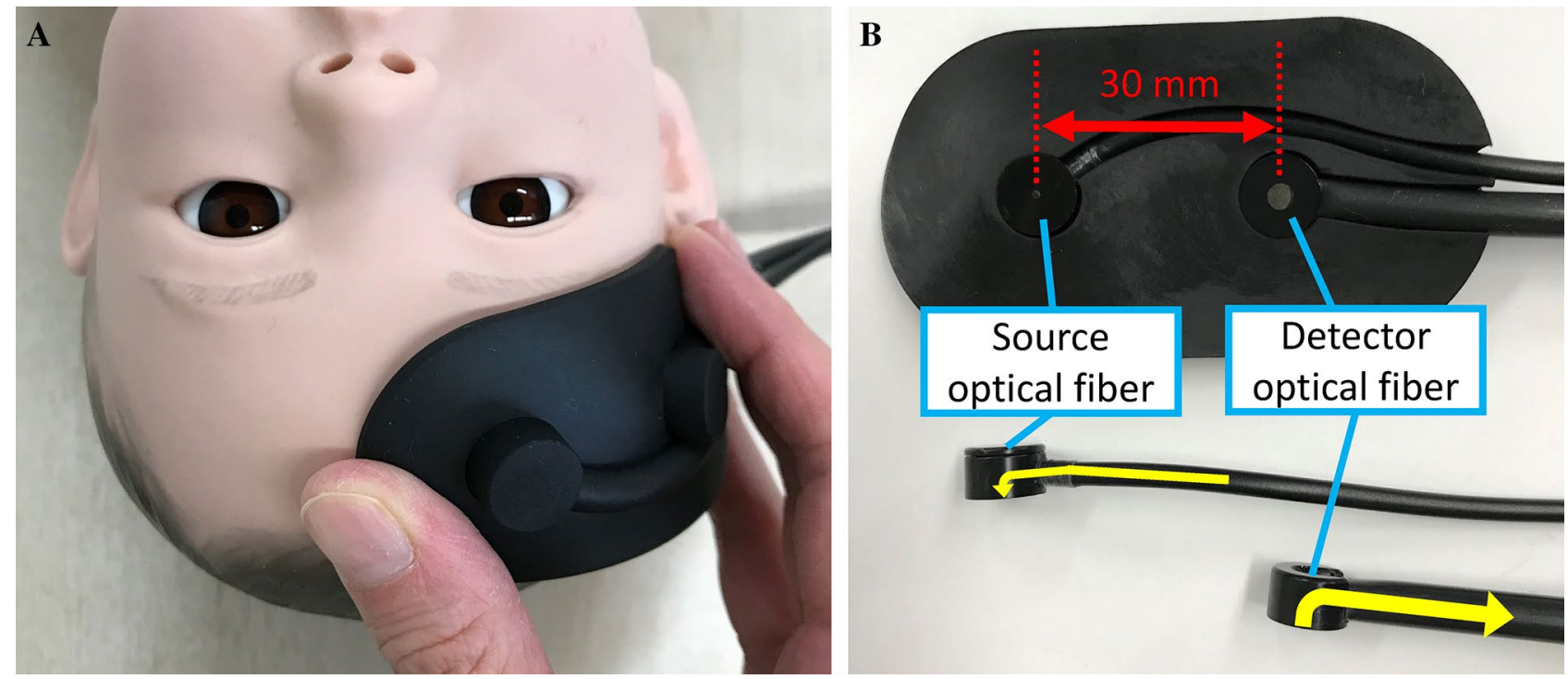

Figure 2. Time-resolved spectroscopy attachment diagram on a simulated infant (mannequin). (A) The light source and detection optodes were positioned on the frontal region. (B) The interoptode distance was $30 \mathrm{~mm}$. The yellow arrow indicates the optical direction of the $90^{\circ}$ bent tip.

$$
\begin{aligned}
\mu \mathrm{a}_{762 \mathrm{~nm}} & =\varepsilon_{762 \mathrm{~nm}}^{\text {oxyHb}}\left[\text { oxyHb]}+\varepsilon_{762 \mathrm{~nm}}^{\text {deoxyHb}}\left[\text { deoxyHb]}+\mu \mathrm{a}_{762 \mathrm{~nm}}^{\text {background }}\right.\right. \\
\mu \mathrm{a}_{800 \mathrm{~nm}} & =\varepsilon_{800 \mathrm{~nm}}^{\text {oxy }}\left[\text { oxyHb]}+\varepsilon_{800 \mathrm{~nm}}^{\text {deox } \mathrm{H}}\left[\text { deoxyHb]}+\mu \mathrm{a}_{800 \mathrm{~nm}}^{\text {background }}\right.\right. \\
\mu \mathrm{a}_{836 \mathrm{~nm}} & =\varepsilon_{836 \mathrm{~nm}}^{\text {oxy }}\left[\text { oxyHb]}+\varepsilon_{836 \mathrm{~nm}}^{\text {deoxyHb}}\left[\text { deoxyHb]}+\mu \mathrm{a}_{836 \mathrm{~nm}}^{\text {backgroungd }}\right.\right.
\end{aligned}
$$

In these equations, $\varepsilon_{\lambda \mathrm{nm}}^{x}$ is the extinction coefficient at $\lambda \mathrm{nm}$, and [oxyHb] and [deoxyHb] are the concentrations of oxyHb and deoxyHb, respectively.

We used a source optical fibre bundle with a diameter of $1 \mathrm{~mm}$ and a detector optical fibre bundle with a diameter of $3 \mathrm{~mm}$, both with a $90^{\circ}$ bent tip and numerical aperture of 0.29 (Fig. 2B). The light emission and detection optodes were positioned on the frontal region at an interoptode distance of $30 \mathrm{~mm}$. The total cerebral $\mathrm{Hb}$ (total $\mathrm{Hb}$ ) concentration, $\mathrm{ScO}_{2}$, and $\mathrm{CBV}$ values were calculated as follows:

$$
\begin{aligned}
& {[\text { total } \mathrm{Hb}]=[\text { oxyHb }]+[\text { deoxyHb }],} \\
& \mathrm{ScO}_{2}(\%)=([\text { oxyHb }] /([\text { oxyHb }]+[\text { deoxyHb }]) \times 100, \\
& \mathrm{CBV}(\mathrm{mL} / 100 \text { g brain tissue })=[\text { totalHb }] \times \mathrm{MW}_{\mathrm{Hb}} \times 10^{-6} /\left(\mathrm{tHb} \times 10^{-2} \times \mathrm{Dt} \times 10\right),
\end{aligned}
$$

where [ ] indicates the $\mathrm{Hb}$ concentration $(\mu \mathrm{M}), \mathrm{MW}_{\mathrm{Hb}}$ is the molecular weight of $\mathrm{Hb}(64,500)$, tHb is the venous $\mathrm{Hb}$ concentration $(\mathrm{g} / \mathrm{dL})$, and $\mathrm{Dt}$ is the brain tissue density $(1.05 \mathrm{~g} / \mathrm{mL})$.

All neonates underwent blood gas analysis, and CBV was calculated from the venous $\mathrm{Hb}$ concentration at $2 \mathrm{~h}$ after birth.

Statistical analysis. Between-group differences in patient characteristics were analysed using the $t$-test. The mean $\mathrm{CBV}$ and $\mathrm{ScO}_{2}$ values were calculated at 10 -s intervals and the $\mathrm{SpO}_{2}$ data were measured at 15-s intervals for $15 \mathrm{~min}$ after birth.

For the parameters measured over time ( $\mathrm{CBV}, \mathrm{ScO}_{2}, \mathrm{SpO}_{2}$, and $\left.\mathrm{HR}\right)$, a linear mixed model was used to analyse the difference between the CS and VD groups at each time point. This is because there are differences in the number of time points measured in different cases. A model was constructed with the parameters measured over time as the dependent variable, subjects as a random factor, and time, groups, and their interaction terms (time $\times$ group) as fixed factors. For each estimate, the least squares mean and its $95 \%$ confidence interval (CI) were calculated. Statistical analyses of $\mathrm{CBV}, \mathrm{ScO}_{2}, \mathrm{SpO}_{2}$, and $\mathrm{HR}$ were performed using SPSS for Windows version 24.0 (IBM Japan, Tokyo, Japan). A two-sided $P$ value $<0.05$ was considered statistically significant.

We then compared oxyHb and deoxyHb values obtained within the first $5 \mathrm{~min}$ by repeated measures twoway analysis of variance followed by post hoc analysis with Sidak's multiple comparisons test to determine the time points when differences were evident. Statistical analyses of oxyHb and deoxyHb were performed using GraphPad Prism 8 (GraphPad Software, La Jolla, CA). A $P$ value $<0.05$ was considered statistically significant.

Ethical approval and informed consent. The study was approved by the Regional Committee on Biomedical Research Ethics of Kagawa University (approval number: H29-042) and conducted in accordance with the Declaration of Helsinki. The parents of all neonates enrolled in the study provided written informed consent before delivery after receiving a full explanation of the research. 


\section{Data availability}

The datasets generated during and/or analysed during the current study are available from the corresponding author on reasonable request.

Received: 30 March 2021; Accepted: 9 September 2021

Published online: 29 September 2021

\section{References}

1. Irestedt, L., Dahlin, I., Hertzberg, T., Sollevi, A. \& Lagercrantz, H. Adenosine concentration in umbilical cord blood of newborn infants after vaginal delivery and cesarean section. Pediatr. Res. 26, 106-108. https://doi.org/10.1203/00006450-198908000-00007 (1989).

2. Hosono, S. et al. Summary of Japanese neonatal cardiopulmonary resuscitation guidelines 2015. Pediatr. Int. 62, 128-139. https:// doi.org/10.1111/ped.14055 (2020).

3. Lu, Y. C. et al. Reevaluating reference ranges of oxygen saturation for healthy full-term neonates using pulse oximetry. Pediatr. Neonatol. 55, 459-465. https://doi.org/10.1016/j.pedneo.2014.02.004 (2014).

4. Dawson, J. A. et al. Defining the reference range for oxygen saturation for infants after birth. Pediatrics 125, e1340-1347. https:// doi.org/10.1542/peds.2009-1510 (2010).

5. Rabi, Y., Yee, W., Chen, S. Y. \& Singhal, N. Oxygen saturation trends immediately after birth. J. Pediatr. 148, 590-594. https://doi. org/10.1016/j.jpeds.2005.12.047 (2006).

6. Urlesberger, B. et al. Regional oxygen saturation of the brain during birth transition of term infants: Comparison between elective cesarean and vaginal deliveries. J. Pediatr. 159, 404-408. https://doi.org/10.1016/j.jpeds.2011.02.030 (2011).

7. Schwaberger, B. et al. Transitional changes in cerebral blood volume at birth. Neonatology 108, 253-258. https://doi.org/10.1159/ 000437347 (2015).

8. Pichler, G. et al. Reference ranges for regional cerebral tissue oxygen saturation and fractional oxygen extraction in neonates during immediate transition after birth. J. Pediatr. 163, 1558-1563. https://doi.org/10.1016/j.jpeds.2013.07.007 (2013).

9. Almaazmi, M. et al. Cerebral near-infrared spectroscopy during transition of healthy term newborns. Neonatology 103, 246-251. https://doi.org/10.1159/000345926 (2013).

10. Pichler, G. et al. aEEG and NIRS during transition and resuscitation after birth: Promising additional tools; an observational study. Resuscitation 84, 974-978. https://doi.org/10.1016/j.resuscitation.2012.12.025 (2013).

11. Tamussino, A. et al. Low cerebral activity and cerebral oxygenation during immediate transition in term neonates-A prospective observational study. Resuscitation 103, 49-53. https://doi.org/10.1016/j.resuscitation.2016.03.011 (2016).

12. Schwaberger, B. et al. Cerebral blood volume during neonatal transition in term and preterm infants with and without respiratory support. Front. Pediatr. 6, 132. https://doi.org/10.3389/fped.2018.00132 (2018).

13. Isobe, K. et al. Measurement of cerebral oxygenation in neonates after vaginal delivery and cesarean section using full-spectrum near infrared spectroscopy. Comp. Biochem. Physiol. Part A Mol. Integr. Physiol. 132, 133-138 (2002).

14. Isobe, K. et al. Changes in cerebral hemoglobin concentration and oxygen saturation immediately after birth in the human neonate using full-spectrum near infrared spectroscopy. J. Biomed. Opt. 5, 283-286. https://doi.org/10.1117/1.429997 (2000).

15. Kusaka, T. et al. Evaluation of cerebral circulation and oxygen metabolism in infants using near-infrared light. Brain Dev. 36, 277-283. https://doi.org/10.1016/j.braindev.2013.05.011 (2014).

16. Morimoto, A. et al. Measurement of the absolute value of cerebral blood volume and optical properties in term neonates immediately after birth using near-infrared time-resolved spectroscopy: A preliminary observation study. Appl. Sci. 9, 2172 (2019).

17. Noori, S. et al. Transitional changes in cardiac and cerebral hemodynamics in term neonates at birth. J. Pediatr. 160, 943-948. https://doi.org/10.1016/j.jpeds.2011.12.008 (2012).

18. Polglase, G. R. et al. Ventilation onset prior to umbilical cord clamping (physiological-based cord clamping) improves systemic and cerebral oxygenation in preterm lambs. PLoS ONE 10, e0117504. https://doi.org/10.1371/journal.pone.0117504 (2015).

19. Aldrich, C. J. et al. The effect of maternal pushing on fetal cerebral oxygenation and blood volume during the second stage of labour. Br. J. Obstet. Gynaecol. 102, 448-453. https://doi.org/10.1111/j.1471-0528.1995.tb11316.x (1995).

20. Peebles, D. M. et al. Relation between frequency of uterine contractions and human fetal cerebral oxygen saturation studied during labour by near infrared spectroscopy. Br. J. Obstet. Gynaecol. 101, 44-48. https://doi.org/10.1111/j.1471-0528.1994.tb13008.x (1994).

21. Peebles, D. M. et al. Changes in human fetal cerebral hemoglobin concentration and oxygenation during labor measured by nearinfrared spectroscopy. Am. J. Obstet. Gynecol. 166, 1369-1373. https://doi.org/10.1016/0002-9378(92)91606-b (1992).

22. Turner, J. M., Mitchell, M. D. \& Kumar, S. S. The physiology of intrapartum fetal compromise at term. Am. J. Obstet. Gynecol. 222, 17-26. https://doi.org/10.1016/j.ajog.2019.07.032 (2020).

23. van Bel, F., Sola, A., Roman, C. \& Rudolph, A. M. Role of nitric oxide in the regulation of the cerebral circulation in the lamb fetus during normoxemia and hypoxemia. Biol. Neonate 68, 200-210. https://doi.org/10.1159/000244238 (1995).

24. Nishida, N. et al. Role of prostanoids in the regulation of cerebral blood flow during normoxia and hypoxia in the fetal sheep. Pediatr. Res. 60, 524-529. https://doi.org/10.1203/01.pdr.0000242268.99726.53 (2006).

25. Lear, C. A. et al. The peripheral chemoreflex: Indefatigable guardian of fetal physiological adaptation to labour. J. Physiol. 596, 5611-5623. https://doi.org/10.1113/jp274937 (2018).

26. Dawson, J. A. et al. Changes in heart rate in the first minutes after birth. Arch, Dis. Child. Fetal Neonatal Ed. 95, F177-181. https:// doi.org/10.1136/adc.2009.169102 (2010).

27. Ijichi, S. et al. Developmental changes of optical properties in neonates determined by near-infrared time-resolved spectroscopy. Pediatr. Res. 58, 568-573. https://doi.org/10.1203/01.Pdr.0000175638.98041.0e (2005).

28. Patterson, M. S., Chance, B. \& Wilson, B. C. Time resolved reflectance and transmittance for the non-invasive measurement of tissue optical properties. Appl. Opt. 28, 2331-2336. https://doi.org/10.1364/ao.28.002331 (1989).

\section{Acknowledgements}

We thank the staff of Hamamatsu Photonics K.K. as well as M.H. and N.O. of the Faculty of Medicine at Kagawa University for their cooperation.

\section{Author contributions}

A.Mo., S.N., and T.K.: substantial contributions to the conception or design of the work; S.N., S.K., and T.K.: securing of the financial support necessary for this project and providing the study materials; Y.Na., A.Mi., S.N., K.N., M.S., K.K., M.A., T.Y., Y.No., J.K., and N.F.: acquisition, analysis, or interpretation of data; M.M., I.K., Y.K., S.K., S.Y., and T.I.: agreement to be accountable for all aspects of the work in ensuring that questions related to the accuracy or integrity of any part of the work are appropriately investigated and resolved. 


\section{Funding}

This study was financially supported by JSPS KAKENHI Grants-in-Aid (Nos. 17K10178, 17K10179, 18K15717, 19K08253, 19K14177, 19K08349, and 20K08159); the RIKEN Healthcare and Medical Data Platform Project; Kagawa University Faculty of Medicine School of Medicine Alumni Association Sanjukai Research Aid (H29-2 and R1-1). The sponsors had no role in the study design, in the collection, analysis, or interpretation of data, in the writing of the manuscript, or in the decision to submit the manuscript for publication.

\section{Competing interests}

The authors declare no competing interests.

\section{Additional information}

Correspondence and requests for materials should be addressed to S.N.

Reprints and permissions information is available at www.nature.com/reprints.

Publisher's note Springer Nature remains neutral with regard to jurisdictional claims in published maps and institutional affiliations.

(c) (i) Open Access This article is licensed under a Creative Commons Attribution 4.0 International

License, which permits use, sharing, adaptation, distribution and reproduction in any medium or format, as long as you give appropriate credit to the original author(s) and the source, provide a link to the Creative Commons licence, and indicate if changes were made. The images or other third party material in this article are included in the article's Creative Commons licence, unless indicated otherwise in a credit line to the material. If material is not included in the article's Creative Commons licence and your intended use is not permitted by statutory regulation or exceeds the permitted use, you will need to obtain permission directly from the copyright holder. To view a copy of this licence, visit http://creativecommons.org/licenses/by/4.0/.

(c) The Author(s) 2021 